\title{
Meaningful social interactions between older people in institutional care settings
}

\author{
GILL HUBBARD*, SUSAN TESTER $\dagger$ and MURNA G. DOWNS**
}

\begin{abstract}
This paper is a contribution to the developing understanding of social relationships in institutional care settings. It focuses on two areas that have been neglected in research: the reasons for and types of social interaction in institutional settings, and the ways in which the context of people's lives shapes social interaction. The paper draws on ethnographic observations conducted in four care settings in Scotland using a symbolic interactionist perspective. It finds that residents communicate and interact, and that the personal, cultural and structural contexts frame social interaction and influence the ways that residents use humour, express sexuality, and show hostility. The paper concludes that residents create social interactions in which action is embedded, but do so within specific structural and cultural contexts. These contexts 'control' resident action by establishing frameworks for the interpretation of meaning. At the same time, each facet of context is 'controlled' by the ways in which residents actively take on the 'role' of others, and project 'self' and a 'label'.
\end{abstract}

KEY WORDS - older people, social interaction, institutional care settings, Scotland.

\section{Introduction}

A long tradition of research has shown the important influence of social relationships in older age on the health dimensions of the quality of life including life satisfaction and emotional, subjective and psychological wellbeing (Cutrona et al. I986; Holmen et al. I994; Lee and Ishii-Kuntz i987; Lee and Shehan I989; Nussbaum 1983; Revenson and Johnson I984; Traupmann et al. 1992). Older people have identified social relationships and social contacts with family and friends as important influences upon their quality of life (Bowling I995; Farquhar I995); and peer relationships

* Department of General Practice, University of Glasgow, Scotland.

$\uparrow$ Department of Applied Social Science, University of Stirling, Scotland.

** Dementia Services Development Centre, University of Bradford, England. 
are perceived as vitally important in the ageing process (Jerrome 1992). Research has shown that within institutional care settings social relationships among older people play important roles in supporting and helping residents (Oleson et al. I998; Powers I988).

Investigations that quantify social interaction in institutional care settings have shown that residents do nothing for many hours, the findings of quantitative research consistently report that institutional care settings are bereft of high levels of social interaction and social activity (Bowie and Mountain I993; Godlove et al. I982; MacDonald et al. I985; McCormack and Whitehead I98I; Mattiasson and Andersson i997; Nolan et al. I995; VanHaitsma et al. 1997; Ward et al. 1992). Moreover, much of the residents' time is spent in social and emotional isolation (McKee et al. 1999). This does not mean, however, that some residents do not socially interact on occasions. Qualitative research has shown that social relationships between residents are often reciprocal and caring, although some may be hostile and unfriendly (Powers I99I, I996; Reed and Roskell Payton I997; Williams and Roberts I995). The most popular activity among the residents is talking, and the most common conversations centre on their feelings about living in the facility (Gutheil I99I).

Institutional care settings may thus be described as places where residents spend most of their time in social isolation, but they may also be characterised as domains with pockets of social interaction between the residents. Perhaps if there were greater knowledge about the types of social interaction, and greater understanding about why residents socially interact, then it might be possible to enlarge these pockets. For example, largely missing from the literature is any understanding of why residents use particular types of social interaction. There is little recognition of the ways in which residents use jokes and irony to make sense of their daily experiences, and although hostility between residents has been identified there is little understanding about its sources, motivations and forms.

There is also a dearth of understanding about sex and sexuality in institutional care settings (Bauer 1999; McLean i994; Miles and Parker I999). In particular, the sexual relationships of residents with dementia are a little understood area of gerontology (Berger 2000; Mayers I994; Post 2000). The predominant views are that older people in institutional care settings are without sexual interests, identities, needs or capabilities, and that expressions of sexuality among residents ought to be repressed (Brown 1989; Glass et al. 1986; Kaas 1978; McCartney et al. I987; McKinley and Drew 1977). At the same time, it is clear that some residents are involved in sexual activity or desire sex (Mulligan and Palguta I99I; Wasaw and Loeb I979; White 1982), and that sexuality is a major determinant of identity (Nay 1992). There is also growing recognition amongst 
healthcare professionals of the importance of sexuality among residents (Holmes et al. 1997), and this has prompted recommendations for managing sexuality in institutional care settings (Archibald I998, 200I; Kessel 2001; Richardson and Lazur i995; Tunstall and Henry 1996; Wallace 1992). Absent from this small but growing literature, however, is any exploration of the different ways in which residents express their sexual selves.

The development of social relationships among residents in institutional care settings is likely to vary both within and between care facilities. Various factors that influence both the quantity and quality of interaction between residents have been identified. These include: personal attributes such as hearing, speech, sight, ambulate and cognitive abilities (Bitzan and Kruzich I990; Retsinas and Garrity 1985; Mor et al. I995; Kovach and Robinson I996); structural attributes such as staffing levels and the physical environment (Moore 1999); and cultural attributes such as the philosophy of care and perceptions of older age (Noelker and Poulshock I984; Reed and McMillan r995; Timko and Moos I990). Largely missing, however, are descriptions of the ways in which personal, structural and cultural facets of context synthesise and shape social interaction.

Existing work on older people's social interaction in institutional care settings has tended to exclude those with the most severe disabilities and with whom communication is most difficult as a result of sensory or cognitive impairments (Chen et al. 2000). It is these residents who are particularly likely to experience social and emotional isolation in all institutional care settings (Armstrong-Esther and Browne I986; Ekman et al. I99I; Schroll et al. I997). Whilst the importance of communication in the care of older people with dementia has been recognised (Killick and Allan 200I), there has been very little study of the ways in which residents with a cognitive impairment seek each other and socially interact (Hubbard et al. 2002; Kelley 1997).

This paper contributes towards our knowledge and understanding of social interaction in institutional care settings by focusing on a relatively neglected area: social interaction among residents, including those with dementia. Descriptions of the ways in which residents socially interact are reported. These social interactions highlight the ways in which residents communicate, use humour, express a sexual self, and act with hostility towards one another.

\section{Descriptions of the care settings}

The social interactions reported in this paper were between residents in four different care settings in Scotland: a dementia unit of a nursing home; 
a floor of the same nursing home designated for older people with physical impairments; another nursing home; and a residential home. These settings are briefly described to indicate where the residents congregated and where social interaction occurred.

One nursing home was purpose-built to house 70 residents. Its ground floor was the dementia unit setting (AI). It has a large reception area, a dining room and three lounges with a television, and a nurses' office. Long corridors connect the bedrooms. Most residents during the day sat in one of the lounges with the television on, although some remained in their rooms and others walked along the corridors. Many of the residents tended to sit in the same lounge each day, while those who stayed in their rooms or walked the corridors did so regularly, and another floor was for older people with physical impairments $\left(D_{4}\right)$. This floor had the same layout as the ground floor, except that there was a larger lounge where the majority of residents sat during the day.

The other nursing home was a converted old house that also had a large purpose-built extension with room for 80 residents $\left(\mathrm{C}_{3}\right)$. On the ground floor there was a large dining room and also a large lounge where the majority of residents congregated in the day. Other residents sat in the busy reception area or the alcoves of the corridor that ran along the side of the dining room where it was relatively quiet. There was a small television lounge but it was rarely used. The bedrooms were on three floors and hardly any of the residents remained in their own rooms during the day. During the evening a few residents who did not go to bed early sat in the corridors outside their rooms. By 8.30 in the evening there were no residents on the ground floor.

Residential home $\mathrm{B}_{2}$ was designed as three separate self-contained units on three floors for 60 residents. Each unit consisted of a long corridor that had its own dining room, small kitchen, two lounges - one of which was for smoking, and bedrooms. Residents sat in the lounges or sat on settees in the lobby area by the lifts. On the ground floor was a large dining room and lounge but residents were encouraged to spend their time in their own unit.

\section{Methods}

The ethnographic study that is reported in this paper aimed to explore perceptions of quality of life of frail older people in institutional care settings. The theoretical framework that was used to explore and analyse social interaction between residents in institutional care settings was symbolic interactionism (Manis and Meltzer i967). This perspective views the social world as phenomenologically constituted, which in this 
particular study meant that the researchers explored the ways in which residents constructed and negotiated meaning through processes of social interaction with others. The strength of an interactionist approach lies in its focus on the negotiation of meaning and therefore of constructing residents as active in their social world. The unit of study was an act of social interaction between residents in the institutional care setting. Concepts of 'self', 'role' and 'labelling' were used to explore the residents' interpretation of social action.

An ethnographic approach was adopted to explore the ways in which residents socially interacted (Hammersley and Atkinson I995). Naturalistic observations were carried out so that the researchers were immersed in the ways in which residents socially interacted and made sense of their own and each other's actions (Angrosino et al. 2000). The researchers took the role of 'observer as participant' to minimise interference with the residents' social interactions and activities (Gold I958). During the observations the researchers reminded the residents that they were there to observe, and they kept their notepads visible and wrote fieldnotes to reinforce the reason for their presence in the residents' social world. On occasions, however, the residents drew the researchers into their social worlds and this provided the researchers with opportunities to explore residents' interpretations of social interactions in the care settings through conversation. Using this approach, the researchers were able to place the residents' interpretations of social interactions in the specific context of the care home.

The majority of residents, including those with sensory or cognitive impairments, gave informed consent or by proxy (Hubbard et al. 200I). Observations were conducted in each care setting over 24 hours on different days of the week, including weekends, for approximately four weeks. Two-hour observation periods were conducted during the daytime between $8 \mathrm{am}$ and $9 \mathrm{pm}$, and one session on the night-shift which was usually from $9 \mathrm{pm}$ until $8 \mathrm{am}$. The observations were conducted in public spaces, including dining rooms, corridors and lounges. Some observations were however carried out in a bedroom if agreed by the resident. The researchers would spend time being with and observing a particular resident or group of residents. Once all the observations had been carried out, each set of fieldnotes was re-iteratively examined for themes. The data software package, $\mathcal{N} u d^{*} i s t$, was used to facilitate data analysis.

\section{Verbal and non-verbal communication}

For those residents who were able to speak and hear, talking was an important form of social interaction. Popular topics of very short 
conversations included the weather and the behaviour of other residents. Two female residents in the residential home $\left(\mathbf{B}_{2}\right)$ talked about the behaviour of another female resident who was being transferred to a nursing home because of severe cognitive impairment. One of them said that she was, 'Shouting and bawling all night'. 'That's terrible', retorted her friend. The first female resident responded, 'Not fair that', and the second female resident replied, 'She's shouting this morning and all'. Other snippets of conversation emanated from happenings in the residents' vicinity. Four female residents were sitting at a dining room table in the dementia unit $\left(\mathrm{AI}_{\mathrm{I}}\right)$ when a chair was scraped along the floor. One said, 'That's a horrible noise', which was a cue for two others to reply, 'Yes'.

Not all talk was conversational because one resident's utterances did not always evoke a verbal response. The following example shows a resident of $\mathrm{B}_{2}$ consciously attempting to interpret the behaviour of another. A female resident saw that another resident was not wearing any shoes or slippers. She asked the researcher, 'I wonder why she sits in her bare feet?' The shoeless woman moaned as if in pain and the other resident asked, 'Are you alright dear?' There was no response.

Hearing impairments prevented verbal conversations. This disability was compounded by the fact that hearing aids were not worn or were mislaid. One resident of $\mathrm{D}_{4}$ described the lack of a hearing aid as one of his 'greatest troubles'. Some residents with verbal impairments circumvented their hearing disability by using non-verbal behaviour to communicate. They used this method in meaningful ways for others to interpret. One female resident of $A_{I}$ who had a hearing impairment mimed rather than spoke as she sat with a group of residents who were making icing sugar. As she beat the sugar and water in a bowl, she lifted and shook her wrist, at the same time crunching her face to indicate that it made her wrist ache. She mimed the words 'icing sugar' to her neighbour and, rather than saying the words out loud, she mimed the numbers as she pointed to and counted the cakes.

\section{Humour and frailty}

Humour was a significant feature of the verbal and non-verbal social interactions among the residents. Exploring the ways in which residents imbued humour into social interaction shows how they interpreted the intentions or the acts of others, and negotiated the meaning of the behaviour. One of the ways in which residents used humour was in relation to their physical frailties, making light of their own and each other's ageing bodies. A male resident of $\mathrm{B}_{2}$ very slowly struggled to lift himself off his 
chair and onto his feet. Once standing up, he looked at a female resident next to him and sang one line of a song, and then remarked, 'I'm going to get ready for lunch'. She replied laughingly, 'Are you going to do a jig?' This question was clearly a joke because he was hardly able to stand up. Joking about frailty was also a means of acknowledging the presence of death.

In dementia unit AI, when a male resident coughed deeply and cleared his throat, another male resident commented, 'You'll last a bit longer yet,' to which the coughing resident laughingly replied, 'Oh aye'. Humour was also used as a means of dissipating worry and concern about accidents. When a female resident of $\mathrm{B}_{2}$ fell off her chair in the dining room and banged her head, her friend shouted, 'Oh Ruby', and looked at her anxiously. When the fallen resident told a carer that she did not feel 'too bad', her friend laughed and said that she must have drunk too much the night before. This encouraged her friend who was still lying on the floor to laugh too.

\section{Practical jokes and teasing}

Residents also played practical jokes and teased one another. They developed shared meanings of particular actions and interpreted them in the context of play-acting. This type of behaviour was often non-verbal and drew the residents with a verbal communicative impairment into the social interactions of the home. Sarah and Bridget, two residents of $\mathrm{B}_{2}$ with severe hearing impairment, participated in several incidents that highlight the ways in which larking about created opportunities to engage with others. When a male resident walked in to the lounge, he pretended to be a professional boxer and threw a couple of mock punches at Sarah; and, as Bridget got up to leave the room, he playfully shadowboxed with her too. Sarah always wore a hand-knitted shawl around her shoulders. A female resident indicated to a carer that she wanted Sarah's shawl. The carer laughed and told Sarah that the other resident wanted her shawl. Sarah joined in the teasing, grabbed her shawl, shook her head, patted the sides of her head with her hands, and then pointed to the female resident to suggest that she was crazy. They all laughed. On another occasion the same female resident who had teased Sarah winked at the researcher and said to Bridget, who sat with a cup of tea in her hands, 'That's my tea Bridget'. Bridget replied, 'No it's not' and as she walked away with her cup of tea she smiled and put two fingers up behind her back to the female resident, who also was laughing.

Humour pervaded discussions about sexual relationships, and female residents in particular amused themselves with such conversation. Two 
female residents of $\mathrm{B}_{2}$ were sitting on a settee with a female carer. One of the residents said that she wanted a man with money, which made her two companions laugh. The other resident teased her friend by saying that she liked one of the male residents. The carer asked whether he had any money, which they all found highly comical, and giggled. When a male resident of dementia unit Ar walked along the corridor in his night-shirt and dressing gown, he provoked great hilarity between two female residents sitting in the lounge. As they spotted the man in his nightwear, one turned to the other and asked, 'Is that the first time you've seen it?' The woman replied, 'I've seen it before. I wouldn't like to sleep with it', which made them both laugh. When the man in the night-shirt walked past once more, the women laughed again, and another male resident sitting in the lounge laughed with them. One of the women joked with him and said, 'Now don't you go and get jealous and buy new nightwear like his'. The man laughed and replied, 'Oh no, no'. When the man in the night-shirt walked past for the third time one of the women said, 'We should all club together and get him a red striped one'. All three residents laughed together. These examples show how the women developed shared meaning to express their sexuality.

\section{Flirtation and affection}

Many of the flirtations that occurred between the men and women residents were embellished with witty remarks, which in turn became avenues for displays of affection. Residents in care home $\mathrm{B}_{2}$ particularly enjoyed flirting with each other. When a female resident walked into the lounge she went up to a male resident who was sitting in a chair and wiggled his ears with her hands. He said to her, 'God's gift to men', to which she responded, 'Some men'. When a female resident stretched out her shapely legs in front of her, a male resident laughed and told her that he was a Presbyterian and that she should not put her legs out like that. She smiled at him.

Flirting was not the only way in which residents expressed warmth and affection for each other. Residents would also pass compliments on what each other were wearing. For example, a male resident of $\mathrm{B}_{2}$ said to a woman who was sitting next to him that he liked the skirt that she was wearing. She smiled, stroked her skirt with her hands and thanked him. A female resident touched another female resident's cardigan and told her that it was nice. Another way that residents showed affection was through proximity and physical contact. Residents would sit next to each other, touch and kiss. When a male resident of $\mathrm{C}_{3}$ walked into the lounge, a 
female resident looked at him, smiled, looked at the empty chair next to her and another further away, and asked, 'That one or that one?' He sat down in the vacant chair next to her. As a female resident of Ar walked into the dining room, she went up to a male resident who was sitting down and gave him kisses on his cheeks. He laughingly told her to get off him. These examples show that the older people in specific situations the meaning of certain behaviour was commonly interpreted as flirtatious and affectionate rather than as rude and obtrusive.

Some of the affection between male and female residents was romantic and sexual. Open displays of romantic liaisons were evident in one particular care home, which suggests that its culture was conducive to residents exhibiting their sexual feelings for one another. Two residents of $\mathrm{C}_{3}$ often sat together in the lounge and held hands. The female resident said that she did not hold anyone else's hand, and described her male companion as her 'special friend'. On one occasion in the dining room, he asked her to put an orange in her bag so that he could eat it later. As he gave her the orange, she held his hand and kissed it. Their relationship was acknowledged and encouraged by the carers. One said to the female resident, 'You've a twinkle in your eye [and] in love with that man'. Another romantically associated couple in the same home also displayed affection for each other. The male resident smiled and stroked the female resident's hand and face as a 'mark of friendship'. She smiled coyly and turned her head gently as he stroked her. She informed the researcher that she enjoyed being stroked and was affectionate only with this man.

Whilst there were no kisses and hand holding between female residents there was evidence of affection. For instance, one female resident in dementia unit Ar placed her arm gently around her friend's back as they walked together towards the dining area. In home $\mathbf{B}_{2}$, a resident helped her female friend take off her cardigan. Not all affection was however welcome or reciprocated. When one female resident of $\mathrm{D}_{4}$ placed her hand on another female resident's knee and gently squeezed it, the woman frowned and moved her hand away. This shows how similar behaviour, in this case touch, is interpreted in different ways through a process of residents taking on the 'role' of the person doing the touching and interpreting the meaning of the action.

\section{Dislike and anger}

Some residents obviously disliked one another and told each other so. As a male resident of $\mathrm{D}_{4}$ entered the lounge, a female resident retorted, 'I don't like you'. He replied, 'I don't like you either'. The behaviour of some 
residents aroused anger. When one resident started to moan aloud, another became increasingly agitated and shouted, 'Oh for Jesus's sake'. One female resident of $\mathrm{D}_{4}$ who repeatedly asked to go to the toilet obviously got on another's nerves, for she shouted, 'You're not needing the toilet at all; go and give her a slap in the mouth'. As a resident sang in the dining room of $\mathrm{D}_{4}$, another said, 'I wish she'd shut up, it sounds terrible'. A female resident pulled a face as she watched another wipe her nose on her sleeve. She mimed the actions, looked at the researcher, raised her eyes in disgust, and said, 'I wouldn't dream of doing that myself. I looked the other way'. Still at $\mathrm{D}_{4}$, a male resident laughingly explained why he did not like a particular female resident: 'There's a lady with a ghastly voice which goes on incessantly. I assume she's a widow 'cause no man could stand it (laughs). I just know her voice which conquers space (laughs). Once when I was in the dining room that woman was spouting away as usual when a chap who was completely off his legs, very military looking, told her to shut up ... It was really funny, he got up and shouted "shut up".

Some residents' behaviour aroused deep hostility and they were 'labelled' by others as idiots, stupid, clowns, funny types, mental and confused. These acts of hostility suggest that residents adopted the 'role' of others to interpret behaviour, and then acted in ways to distance themselves from the role of idiot or clown. This projection of 'self' as someone who was not a 'funny type' suggests that they were aware of how certain behaviour would be interpreted by others. Two female residents of $\mathrm{B}_{2}$ spoke to one another about a resident with severe cognitive impairment who was moaning. One said, '[She] sits in all night with her cover. She should be in her bed', to which the other responded, 'I'd get rid of her. It's a waste of time bringing the doctor'. One female resident in dementia unit Ar caused considerable consternation when she entered a lounge, and asked, 'Am I in the right place?' Another female resident answered crossly, 'Come in and sit down ... She's a right clown'. The resident who had just entered asked, 'Is that right, sitting here?' to which the other responded sternly, 'Sit, sit', and raised her eyes to the ceiling with a look of disapproval. 'Can I come down there? Can I get something from there?' asked the resident, which provoked the other resident to shout, 'Shut your mouth'.

Some of the residents vented their dislike by segregating themselves so that they did not have to interact with those residents with whom they did not want to socialise. There was a smoking lounge in dementia unit AI that had been captured by a particular group of mostly male residents, whereas another lounge was usually occupied by women. When the female resident who had been shouted at and described as a 'clown' attempted to enter the smoking lounge, one of the men waved her away 
and told her to sit in the other lounge. He looked at the researcher and raised his eyes up and down in disgust. Other residents of Ai placed gates on their doors to prevent others from entering. One male resident with a gate on his door sat in his room all day because he did not like to socialise with others. A female resident who liked to walk up and down corridors and enter rooms in the dementia unit explained, 'He's greetin (crying) when you goes to the room with the gate. Who doesn't want (pause), lonely (pause). He forces us away'.

Although evidence and displays of a severe mental confusion usually provoked hostility, on rare occasions a resident's mental frailty also became a source of amusement. When a male resident walked into a lounge in dementia unit Ar with a rather large, protruding stomach, one of the female residents said, 'Here's somebody coming in, come in. Who's that with the baby? One of the girls is it?' The male resident patted his stomach and said, 'Here's the baby'. The female resident asked, 'What's that a chicken?'. The male resident laughed and replied, 'No twins,' and walked out of the lounge. When he returned a couple of minutes later she asked again, 'Here's somebody, who is it?' The male resident smiled and replied, 'Nat King Cole'. Not all residents were unsympathetic to those residents with a cognitive impairment. For example, one female resident of $\mathrm{B}_{2}$, referring to another with a perceived cognitive impairment, said to a male resident, 'They should be in another place, folk that are confused,' to which he replied, 'That's not very Christian-like'.

\section{Contexts for social interaction}

Institutional care settings for older people are not totally barren domains of solitude and emptiness. Whilst residents may not always be engaged, they do communicate and they do interact. Our findings show residents talking about sexual relationships, flirting, joking, teasing, being affectionate, and acting with hostility. Their social interactions reveal the older person making sense of the presence of others, interpreting behaviours, and showing an awareness of 'self'. It is the older person's agency that rises above the hours of nothingness so characteristic of institutional care settings.

Personal, cultural and structural facets of context served to frame social interaction and the interpretation of meaning, and influenced the ways in which residents used humour, expressed their sexuality, and showed hostility. Speech and hearing impairments were personal attributes that influenced the ways in which residents socially interacted. Non-verbal 
behaviour was used in meaningful ways for others to interpret, and situations were created in which shared meaning was constructed through interpretation of non-verbal action. In this way, residents provided a framework for socially interacting in humorous ways. Practical jokes and teasing became a medium for including residents with sensory impairments into the social interactions of the institutional care setting. Slap-stick comedy was a non-verbal inclusive strategy adopted to entertain and also to develop relationships with others, including those with sensory impairments.

Physical frailty was another personal attribute that framed the ways in which residents socially interacted. Simple, everyday acts such as coughing and getting up out of a chair were acts that took on new meaning. A framework of shared meaning about the frail body had developed, with irony being the medium in which acts were interpreted to create meaning. Cognitive impairments also influenced the social interaction. Acts of hostility were directed towards residents whose behaviours, such as staying up through the night, were interpreted by others as 'stupid'. Once 'labelled', their behaviour was repeatedly interpreted in this way. Through acts of 'labelling', residents projected a 'self' that was not 'mental' or 'stupid', and, by colonising public space, the residents strove to protect and retain this sense of 'self'.

The cultural context also had a bearing on social interaction, and was created and mediated by the development of shared meaning by both professional caregivers and residents. Our study shows sexuality in institutional care settings being expressed in two forms. In one care setting, male and female residents who displayed acts of affection such as holding hands, kissing and stroking each other were romantically paired. The labels 'girlfriend' and 'boyfriend' was used by residents and care staff alike to define the relationship. In another care setting, the framework constructed to express sexuality was flirtatious. The intention of the act, for example, of touching and kissing was interpreted in this framework. Flirtation, by definition, has sexual connotations and this became the medium in which residents could project a sexual 'self'. These examples show how contexts for interpreting meaning and expressing a sexual 'self' are constructed by residents and care staff. What is not clear, however, is the extent to which these contexts can be re-framed. For instance, our research did not reveal the implications for the residents who wanted to develop sexual relationships that involved sexual intercourse, nor the implications for lesbian and gay relationships.

The structural context, such as the layout of the building, also shaped social interaction. Institutional care settings were arenas in which residents negotiated personal space within public space. Residents occupied lounges 
to avoid socialising with those whom they labelled 'funny types'. Physical space was organised by residents as a way of projecting a 'self' that was not 'mental' or 'stupid'. The use of gates on room doorways was another strategy deployed by residents in one particular care setting to avoid contact with others. The physicality of the care setting was made use of by residents to 'label' others and to preserve a sense of 'self'. A framework for social interaction and interpretation of meaning was thus given solid, physical durability.

The institutional care setting is the locus in which residents and professional carers produce and reproduce frameworks for developing shared meaning. The everyday life of the care setting is one in which residents play creative, active and meaningful roles. Our findings show that residents create social interactions in which action is embedded, but do so within specific structural and cultural contexts. These contexts 'control' resident action by establishing patterns of conduct and frameworks for interpretation of meaning. At the same time, each facet of context is 'controlled' by the ways in which residents actively take on the 'role' of others, project a 'self' and 'label'. A synthesis arises in which residents change the contexts that are simultaneously changing them. Further research is required into the ways in which personal, cultural and structural contexts connect, combine and influence residents' quality of life and the quality of care.

\section{Acknowledgements}

This paper is based on a research project (L480 25 4023) of the United Kingdom Economic and Social Research Council research programme Growing Older: Extending Quality Life. Thanks are due to the managers and staff of the nursing and residential homes in which the fieldwork took place. We are particularly grateful to the residents whom we observed.

\section{References}

Angrosino, M. and Mays de Pérez, K. 200o. Rethinking observation: from method to context. In Denzin, N. and Lincoln, Y. (eds), Handbook of Qualitative Research, 2nd Edition. Sage, London, 673-702.

Archibald, C. 1998. Sexuality and sexual needs. In Benson, S. (ed.), The Care Assistant's Guide to Working with People with Dementia. Hawker, London, I45-5.

Archibald, C. 200r. Resident sexual expression and the key worker relationship: an unspoken stress in residential care work. Practice, 13, I, 5-12.

Armstrong-Esther, C. and Browne, K. I986. The influence of elderly patients' mental impairment on nurse-patient interactions. Fournal of Advanced Nursing, 19, 264-7I. 
Bauer, M. 1999. The use of humor in addressing the sexuality of elderly nursing home residents. Sexuality and Disability, 17, 2, I47-55.

Berger, J. 2000. Sexuality and intimacy in the nursing home: a romantic couple of mixed cognitive capacities. Fournal of Clinical Ethics, $\mathbf{1}$, 4, 309-13.

Bitzan, J. and Kruzich, J. I99o. Interpersonal relationships of nursing home residents. The Gerontologist, 30, 3, 385-90.

Bowie, P. and Mountain, G. I993. Using direct observation to record the behaviour of long-stay patients with dementia. International Journal of Geriatric Psychiatry, 8, 857-64.

Bowling, A. 1995. The most important things in life. International fournal of Health Sciences, 5, 4, I $69-75$.

Brown, L. I989. Is there sexual freedom for our aging population in long-term care institutions? Journal of Gerontological Social Work, $\mathbf{1 3}, 3 / 4,75-93$.

Chen, Y., Ryden, M., Feldt, K. and Savik, K. 2000. The relationship between social interaction and characteristics of aggressive, cognitively impaired nursing home residents. American Fournal of Alzheimer's Disease, I5, I, IO-I7.

Cutrona, C., Russell, D. and Rose, J. I986. Social support and adaptation to stress by the elderly. Fournal of Psychology and Aging, I, I, 47-54.

Ekman, S., Norberg, A., Viitanen, M. and Winblad, B. I99. Care of demented patients with severe communication problems. Scandinavian fournal of Caring Science, 5, 3, 163-70.

Farquhar, M. i995. Elderly people's definitions of quality of life. Social Science and Medicine, 41, IO, I439-46.

Glass, J., Mustian, R. and Carter, L. I986. Knowledge and attitudes of health-care providers toward sexuality in the institutionalized elderly. Educational Gerontology, I2, 465-75.

Godlove, C., Richard, L. and Rodwell, G. I982. Time for Action: An Observation Study of Elderly People in Four Different Care Environments. Social Services Monographs, Research in Practice, Joint Unit for Social Services Research, University of Sheffield, Sheffield.

Gold, R. 1958. Roles in sociological field observations. Social Forces, 36, 217-23.

Gutheil, I. I99I. Intimacy in nursing home friendships. Fournal of Gerontological Social Work, I 7, I/ $2,59-73$.

Hammersley, M. and Atkinson, P. 1995. Ethnography: Principles in Practice, 2nd Edition. London, Tavistock.

Holmen, K., Ericsson, K. and Winbald, B. I994. Loneliness and living conditions of the oldest old. Scandinavian Fournal of Social Medicine, 22, I, I5-I9.

Holmes, D., Reingold, J. and Teresi, J. 1997. Sexual expression and dementia. International Fournal of Geriatric Psychiatry, 12, 695-701.

Hubbard, G., Downs, M. and Tester, S. 200I. Including the perspectives of older people in institutional care during the consent process. In Wilkinson, H. (ed.), The Perspectives of People with Dementia. Jessica Kingsley, London, 63-82.

Hubbard, G., Cook, A., Tester, S. and Downs, M. 2002. Beyond words: older people with dementia using and interpreting non-verbal behaviour. Journal of Aging Studies, I6, $3, \mathrm{I} 55^{-67}$.

Jerrome, D. 1992. Good Company: An Anthropological Study of Old People in Groups. Edinburgh University Press, Edinburgh.

Kaas, M. 1978. Sexual expression of the elderly in nursing homes. The Gerontologist, $\mathbf{I 8}, 4,372-8$.

Kelley, M. I997. Social interaction among people with dementia. Fournal of Gerontological Nursing, 23, I6-20.

Kessel, B. 200I. Sexuality in the older person. Age and Ageing, 30, 2, I2I-4.

Killick, J. and Allan, K. 200I. Communication and the Care of People with Dementia. Open University Press, Buckingham. 
Kovach, S. and Robinson, J. I996. The roommate relationship for the elderly nursing home resident. Fournal of Social and Personal Relationships, r3, 4, 627-34.

Lee, G. and Ishii-Kuntz, M. I987. Social interaction, loneliness, and emotional well-being among the elderly. Research on Aging, 9, 4, 459-82.

Lee, G. and Shehan, C. I989. Social relations and the self-esteem of older persons. Research on Aging, II, 4, 427-42.

MacDonald, A., Craig, T. and Warner, L. I985. The development of a short observation method for the study of the activity and contacts of old people in residential settings. Psychological Medicine, $\mathbf{1 5}$, i67-72.

McCartney, J., Izeman, H., Rogers, D. and Cohen, N. 1987. Sexuality and the institutionalized elderly. Fournal of the American Geriatrics Society, 35, 33-3.

McCormack, D. and Whitehead, A. I98I. The effect of providing recreational activities on the engagement levels of long-stay geriatric patients. Age and Ageing, ro, 287-9I.

McKee, K., Harrison, G. and Lee, K. 1999. Activity, friendships and wellbeing in residential settings for older people. Aging and Mental Health, 3, 2, I43-52.

McKinley, H. and Drew, B. 1977. The nursing home: death of sexual expression. Health and Social Work, 2, $180-7$.

McLean, A. 1994. What kind of love is this? The Sciences, September/October, 36-9.

Manis, J. and Meltzer, B. 1967. Symbolic Interaction: A Reader in Social Psychology. Allyn and Bacon, Boston, Massachusetts.

Mattiasson, A. and Andersson, L. 1997. Quality of nursing home care assessed by competent nursing home patients. Fournal of Advanced Nursing, 26, ini7-24.

Mayers, K. 1994. Sexuality and the patient with dementia. Sexuality and Disability, 12, 3, 2I3-I9.

Miles, S. and Parker, K. 1999. Sexuality in the nursing home: iatrogenic loneliness. Generations, Spring, 36-43.

Moore, D. 1999. Dissonance in the dining room: a study of social interaction in a special care unit. Qualitative Health Research, 9, I, I33-55.

Mor, V., Branco, K., Fleishman, J., Hawes, C., Phillips, C., Morris, J. and Fries, B. 1995. The structure of social engagement among nursing home residents. Fournal of Gerontology, $\mathbf{5 o B}$, I, I-8.

Mulligan, T. and Palguta, R. I99ı. Sexual interest, activity and satisfaction among male nursing home residents. Archives of Sexual Behavior, 2o, 2, 199-205.

Nay, R. 1992. Sexuality and aged women in nursing homes. Geriatric Nursing, I I-I 2, 312-I4.

Noelker, L. and Poulshock, S. I984. Intimacy: factors affecting its development among members of a home for the aged. International Fournal of Aging and Human Development, 19, 3, I77-89.

Nolan, M., Grant, G. and Nolan, J. 1995. Busy doing nothing: activity and interaction levels amongst differing populations of elderly patients. Fournal of Advanced Nursing, 22, 528-38.

Nussbaum, J. 1983. Relational closeness of elderly interaction: implications for life satisfaction. Western Fournal of Speech Communication, 47, 229-43.

Oleson, M., Torgerud, R., Bernetter, D., Steiner, P. and Odiet, M. I998. Improving nursing home quality of life: residents helping residents. American Fournal of Alzheimer's Disease, $138-46$.

Post, S. 2000. Commentary on sexuality and intimacy in the nursing home. Fournal of Clinical Ethics, $\mathbf{1 1}, 4,314^{-1} 7$.

Powers, B. I988. Social networks, social support, and elderly institutionalized people. Advanced Nursing Science, ro, 2, 40-58.

Powers, B. г991. The meaning of nursing home friendships. Advance Nursing Science, 14, 2, $4^{2-58}$. 
Powers, B. 1996. Relationships among older women living in a nursing home. Fournal of Women and Aging, 8, 3, I79-98.

Reed, J. and MacMillan, J. I995. Friendship - the proper focus of care? Reviews in Clinical Gerontology, 5, 229-37.

Reed, J. and Roskell Payton, V. I997. Understanding the dynamics of life in care homes for older people: implications for de-institutionalizing practice. Health and Social Care in the Community, 5, 4, 26I-8.

Retsinas, J. and Garrity, P. I985. Nursing home friendships. The Gerontologist, 25, 4, 376-8I.

Revenson, T. and Johnson, J. I984. Social and demographic correlates of loneliness in late life. American Fournal of Community Psychology, 12, I, 7I-85.

Richardson, J. and Lazur, A. 1995. Sexuality in the nursing home patient. American Family Physician, 5I, I2I-4.

Schroll, M., Jonsson, P., Mor, V., Berg, K. and Sherwood, S. 1997. An international study of social engagement among nursing home residents. Age and Ageing, 26, S2, 55-9.

Timko, C. and Moos, R. 199o. Determinants of interpersonal support and self-direction in group residential facilities. Journal of Gerontology, 45, 5, I84-92.

Traupmann, J., Eckels, E. and Hatfield, E. 1992. Intimacy in older women's lives. The Gerontologist, 22, 6, 493-8.

Tunstall, P. and Henry, M. I996. Approaches to resident sexuality. Fournal of Gerontological Nursing, 42, 37-42.

VanHaitsma, K., Lawton, P., Kleban, M., Klapper, J. and Corn, J. 1997. Methodological aspects of the study of behavior in elders with dementing illness. Alzheimer Disease and Associated Disorders, II , 4, 228-38.

Wallace, M. 1992. Management of sexual relationships among elderly residents of long-term care facilities. Geriatric Nursing, 13, 6, 308-II.

Ward, T., Murphy, E., Procter, A. and Weinmans, J. 1992. An observational study of two long-stay psychogeriatric wards. International Fournal of Geriatric Psychiatry, 7, 21 I-I7.

Wasow, M. and Loeb, M. 1979. Sexuality in nursing homes. Fournal of the American Geriatrics Society, 27, 2, 73-9.

White, C. I982. Sexual interest, attitudes, knowledge, and sexual history in relation to sexual behavior in the institutionalized aged. Archives of Sexual Behavior, II, I, I I-2I.

Williams, B. and Roberts, P. I995. Friends in passing: social interaction at an adult day care center. International Fournal of Aging and Human Development, 41, I, 63-78.

Address for correspondence:

Accepted 24 Fuly 2003

Gill Hubbard, Department of General Practice, 4 Lancaster Crescent, Glasgow Gi2 oRR, Scotland.

e-mail:gh77c@clinmed.gla.ac.uk 